\title{
Editorial
}

Public Health Nutrition as a field of practice is rarely uncomplicated. Nutrition-related health problems are multi-factorial, involve numerous stakeholders and are often the result of socio-economic, political, cultural and/or environmental forces operating outside the influence of individuals. This presents challenges such as identifying what are the determinants of problems that present, who are the stakeholders, what are the strategies most likely to be effective in changing these determinants and how to evaluate the effect of these strategies on the public health. This complexity demands that the organised response to public health nutrition problems also needs to be complex, multi-strategic and sustained.

Organising effort and advocating for the public health requires that we understand the prevailing forces that work against the public health. The processed food industry is one example of such a force. The discussion about the impact of Bush Administration policy influenced by food industry lobbying on the World Health Organization 2004 Global Strategy on diet, physical activity and health, in earlier editions of this journal, is a case in point ${ }^{1}$. At a more local level, the food industry is also active in efforts to covertly limit the advocacy efforts of professional organisations through sponsorship programmes that tend to compromise the integrity of organisations that enter into such relationships ${ }^{2,3}$. Many conference delegates at the recent national conference of the Dietitians Association of Australia and the International Congress of Dietetics in Chicago in May, were disturbed to see trade displays from the world's most ubiquitous takeaway food and soft drink companies in these forums. Good intersectorial partnership development or the neutralisation of the capacity of professional organisations to advocate for the public good? I refer readers to Geoffrey Cannon's Out of the Box contribution in the April edition of this journal for a more in-depth commentary on these issues ${ }^{4}$.

In this editorial, I highlight two papers that reinforce the importance of food policy analysis, advocacy and intervention research in effective public health nutrition practice. In their paper titled 'Public health nutrition and food policy', Caraher and Coveney ${ }^{5}$ reflect on food policy in Australia and the United Kingdom and present important arguments about the need to include food policy as a focus of analysis and intervention. They argue that our focus in public health nutrition has in the past been limited to the nexus between food and health (the consumption and nutrition sub-systems) rather than including consideration of the upstream components of the food and nutrition system such as food production, processing and related policy. This recognises the need to look beyond the capacity of individuals to the structural determinants of nutrition-related health problems. Food policy analysis requires consideration of benefits and costs associated with policy. Policy has an important effect of moulding the environment populations live in, including those that effect what we eat and how we move. As a result, it needs to be a focus of public health nutrition effort.

In an earlier editorial in this journal Barrie Margetts has commented on the importance of intervention research in public health nutrition ${ }^{6}$. In their paper reviewing the effectiveness of agricultural interventions in improving nutrition outcomes, Berti and colleagues ${ }^{7}$ respond to the challenge to demonstrate and analyse intervention effectiveness, heard so often in our field. In their review of the peer-reviewed and grey literature they identified and critiqued 30 agricultural interventions that included measures of impact on nutrition status. What is innovative about Berti et al.'s analysis, is the assessment of different categories of capital or assets invested in each intervention. This provided an opportunity to comment on the capital investments needed to promote likelihood of nutritional status improvements resulting from agricultural interventions. A key finding of this review reported by Berti et al. is the central importance of human capital development via nutrition education. This observation in a sense contradicts Caraher and Coveney's assertion that greater emphasis should be directed to structural change. These different positions simply reinforce the earlier comment that public health nutrition needs multi-strategic approaches, and that no individual strategy approach will be optimally effective in isolation of other complementary strategies.

A feature of a vibrant and learning organisation of practitioners is their willingness to engage in debate and encourage consideration of different points of view. Please consider making a contribution to debate amongst the Public Health Nutrition readership by submitting letters to the editor, on points raised here or in response to articles presented in this and future editions of this journal.

\section{Roger Hughes}

Deputy Editor

\section{References}

1 Cannon G. Why the Bush administration and the global sugar industry are determined to demolish the 2004 WHO global 
strategy on diet, physical activity and health. Public Health Nutrition 2004; 7: 369-80.

2 Nestle M. Food company sponsorship of nutrition research and professional activities: a conflict of interest? [Commentary]. Public Health Nutrition 2001; 4: $1015-22$.

3 Dixon J, Sindall C, Banwell C. Exploring the intersectoral partnerships guiding Australia's dietary advice. Health Promotion International 2004; 19: 5-13.
4 Cannon G. Out of the Box. Public Health Nutrition 2004; 7 253-6.

5 Caraher M, Coveney J. Public health nutrition and food policy. Public Health Nutrition 2004; 7: 591-8.

6 Margetts B. Editorial. Public Health Nutrition 2003; 6: 727-8.

7 Berti PR, Krasavec J, FitzGereld S. A review of the effectiveness of agriculture interventions in improving nutrition outcomes. Public Health Nutrition 2004; 7: 599-609. 